\title{
When the Needs of Multicultural Classroom are Ignored: An Ethnographic Study in Nepal
}

\author{
Meenakshi Dahal
}

\begin{abstract}
The teaching-learning process begins with the interaction between the teachers and the children. Without two-way interaction between student and teachers the process is incomplete. Using ethnographic research methods, this paper aims to analyze the role of teachers in a multicultural classroom. Attempt is made to do so by exploring and understanding the school culture and its impact on children's learning as well as the perception of the teachers in its processes. It is found that the teachers' cultural understandings and the children's cultural background is not adequately addressed in the teaching-learning process.
\end{abstract}

Keywords: socio-cultural context, learning and development, school, language of instruction

\section{Introduction}

Socio-cultural environment shows the relationship between individuals and their environment within the similar cultural context and social settings. The sociocultural context here is the environment of the community, where children are growing up and develop holistically. I take the culture as an everyday part of life; as Papalia, Olds, and Feldman (2005) expressed "the culture is the part of everyday world, it is neither above nor beyond". There is no way to distinguish the cultural aspects from other dimensions of the society. There is a complete fusion of the social and the cultural aspects (Edles, 2001, p. 4) and community easily accepts the fusion. Therefore, the definition of culture includes "all elements of social life" (Edles, 2001, p 4). Socio-cultural approaches to learning and development emphasize the interdependence of social and individual processes in the co-construction of knowledge.

Each child is unique in nature. The individuals' nature is shaped by the genes they carry and the environment they grow in. The nurturing environment depends on the sociocultural background of the family and society. The early environment has long effects on an individual's potentials for future productivity (Evans, Myers \& IIfeld, 2000). "...Children are active seekers of knowledge and they emphasize the profound effects of rich social and cultural contexts on their thinking during the learning process" (Berk, 2009, p. 264).

Thus, social and cultural background can be seen in the learning patterns of the children. Socio-cultural environment demonstrates the relationship between individuals and others in the similar cultural context and social settings. Interaction with people and environment promotes children's cognitive and linguistic capability. This process of interaction and interpretation whether in the classroom or elsewhere, supports for meaning making and helps develop complex understanding. Children construct knowledge from the environment receiving actively from others and they use this knowledge depending on their cultural environment (Powell, \& Kalina, 2009).

There are socially and culturally diverse learning environments in communities. Such environment creates variation in the learning process. These environments can be cultural or social. Cultural variations influence the children's ability to learn (Berk, 2009, p. 269). In a country like Nepal where a society is built with various cultural groups, the individual differences are distinctly noticeable. The interaction of children with adults and peer groups is also influenced by the cultures and plays significant roles in the learning process. Activities provided in a group help children to internalize and follow societal ways of thinking and behaving (Papalia, Olds, \& Feldman, 2005, p. 42). Learning and development are interrelated terms. When children develop, they are developing their learning ability together with other capabilities.

The social environment of the classroom in a culturally heterogeneous community is composed of many different cultural representations. Each of the children have different perceptions and knowledge which in turn may differ from and challenge the teachers' knowledge. On the other hand, the classroom can play the role of the social mediator for individual knowledge development. Through discussions and conversations, teachers and children can come to the common understanding which can lead to developing shared meanings and new knowledge. Analyzing others' perspectives and drawing meanings together helps to create a new knowledge in a classroom. No classroom environment is an isolated box. It is a part of a wider community (of school and beyond) which has cultural practices and social norms. This may lead a student into confusion regarding home and school's socio-cultural context.

Socio-cultural elements in this study are the 
environments where children mostly spend their time in learning situations and enable students to negotiate various "symbolic system such as language, codes and practices" (Edles, 2001, p. 6). They are: home settings, school settings and neighborhood settings. These settings provide children opportunities to interact with diverse group of people in a meaningful way that enables children to develop as healthy and fully functioning human-beings (Munger, 2007).

Children learn their language at home. Learning in a mother tongue is a right of the children. Also, using mother tongue based language enabled children to learn further as these indigenous languages are a source of knowledge. Language provides with a basis for understanding of the situation in a given context. Thus language becomes a resource, as a tool for learning for a child. However, it is crucial to note that language-as right and language-asresource are not mutually exclusive (Awasthi, 2004).

Childhood and adolescence is a time when many developmental trajectories are established. It is important that the environments where children spend their time are designed in ways that optimize their opportunities to learn skills that will help them become healthy successful adults. Positive environments for children promote the development of competence and provide opportunities for beneficial relationships (Kemp, Whittaker \& Tracy 1997, as cited in Munger, 2007).

This article analyzes the role of teachers and school environments for the learning and development of children in a multicultural and multilingual context. Here, the school and home environment of the children has been taken into consideration.

\section{Methods and Methodology}

The study was conducted following the ethnographic research approach. The research was done in Nawalparasi, one of the most diversely populated districts in the western part of Nepal. The district is a destination for the people migrating from northern hill region of Nepal and is socially and culturally diversified with multi ethnic, multicultural and multilingual populations. According to Central Bureau of Statistics (CBS, 2012) the population of the district is 643,508 . The population according to caste/ ethnic groups in Nawalparsi are; Magar, 112,889 (17.54\%), Brahman Hill 111947 (17.39\%), Tharu 96973 (15.06\%) and Chhetri 39878 (6.19\%). Remaining minorities are hill Dalit, Terai Dalit, Muslim and other ethnic groups. The economy of the people here are depends mostly in agriculture.

\section{Study Area and Respondents}

On the basis of the composition of the mixed socio-cultural settlement, two heterogeneous communities were selected from two Village Development Committees (VDCs) of Nawalparasi district., in order to acquire rich information on the socio cultural issues. One school from each of the VDCs were selected on the basis of the following criteria: a) the community schools with Early Child Care and Development (ECCD) center / Pre-primary class, b) schools with children from at least three different ethnic groups leading to multi-cultural and multilingual classroom environment, and c) schools with children who speak different languages as their mother tongues.

\section{Participants}

Eight students, four from each school, were selected as participants. The age of the students varied from 10 to 13 years. There were four girls (two from each school) and four boys from different ethnic groups. I covered Bote, Kumal, Chaudhary, Pariyar, B. K, and Magar which are so called 'lower' social classes. They are discriminated and in many conservative houses these groups are regarded as untouchable to the "high class". I have also covered other students from the schools in the course of my school visit and classroom observations.

I also interviewed the parents of these students as well as other parents for richer information. Four teachers from each school were interviewed in the process as well. Furthermore, I have discussed with school management committee members, VDC secretary and other relevant stakeholders to add values as well as to verify the received information.

\section{Researcher's Positionality}

Ethnography is an ethical commitment from the beginning to each step of the research and writing (Madden, 2010). Thus, I made the efforts to maintain dignity, privacy and safety of the study population. Keeping the trustworthiness of the research process in mind, the study was detached from other economic and political influences. My positionality was both as an insider and an outsider. Due to my prior involvement in schools and pre-school programs I have been as an insider. I was well familiar with the school culture. So while talking to the teachers, observing children and talking to their parents I felt like an insider. However, I presented myself as an outsider without any bias. I followed participatory and non- participatory observation (Gobo, 2010). I played with children, sang their songs, listened to stories and took part in the discussions. I was well aware of my research paradigms and my positions. I have shared my observations and clarified my confusions by the series of conversations and communications with teachers, students and the parents without any imposition from my behalf.

\section{Data Generation Process}

The data generation process was started from April 2011. It was a prolonged process that reached completion after almost six months. I visited each place six times and stayed for ten days for each visit. During my visits, I discussed with parents, teachers and other local people regarding the school, education and schooling and also observed their daily life very closely. All data were gathered from the field with explicit permission from the participants. In accordance with the qualitative research tradition (Denzin 
\& Lincoln, 2005), multiple data sources were applied and collected. Data generation and collection process was followed using multiple tools. The data collection methods included: interviews, observations, diary, documents reviews, etc. (Hammersley \& Atkinson, 1995, p. 173).

\section{Data Analysis}

Data analysis was done by following different steps; such as, collecting information (transcripts, field notes, records), transcribing interviews and observation records, organizing the information, coding the data and interpreting the meaning (Creswell 2009 p. 185). After reviewing all the data sources, the materials (interview transcripts and follow-up notes, observation notes, and physical artifacts) were coded manually and preliminary meaning was generated from the interviews, observation field notes, and participant artifacts. The qualitative data analysis proceeded from noting patterns and themes to arrive at comparisons and contrasts to determine conceptual explanations of the study" (Dey, 2003, p. 54; Huberman and Miles, 1983). The data were cross-checked for maintaining the quality, revised using different data sources of information by examining the evidence from the sources; also reviewed alongside were the interview transcripts, observation notes and narrative texts. To maintain quality, member checking was used to corroborate and feedback (Stake, 1995) from the participants were sought during analysis and the interpretation. Most of the research participants were given opportunities to review data materials and provide a further response to the research questions.

\section{School: Environment for Learning and Development}

School is a miniature society (Chapman, 2010). School represents a structure that has a strong link with the nation. Schools play important roles in the society. I found that people have trust in schools; by sending their children to school they believe that their children will be better human beings.

All parents in my study area were concerned about their children's education, but there was a lack of frequent visits to the school from parents to ask about their children's educational improvements. I felt people believe school to be a "symbol of power" (Covaleskie, 1993). The school shows its authority to the children's future. They think teachers are knowledgeable people and have power to dominate over the students. This understanding created a huge gap between the school (teachers) and the community people. "In school the teacher is institutionally defined as superior to any student in knowledge of subject matter and in responsibility as a good citizen" (Ballantine $\&$ Spade, 2004). And the community people within the research group expressed schools to be supreme institutions and teachers to be well disciplined and knowledgeable people. School management committee and the teachers also had similar understanding that they have "power" to control a student. This is reflected in the conversation with parents, and the children.

The school represents a multicultural society and follows the national education policy of Nepal accordingly. Ideally, the school is considered as the premise where all cultures and languages have equal space. Each child can express their views and play and learn freely. In the same vein, teachers believe their role is to support children in their learning and development based on their own cultural background. But implementing this idea in a real classroom will have challenges, mostly due to the gap in understanding between the teachers and students. When asked about their multicultural classroom, Mr. Rajesh, a teacher from one of the study schools said, "There might be some other students who are from a different culture. In a particular cultural majority groups they may face psychological problem in learning activities. We do not say that multi culture in school is not good, it also has positive impact on society. All the students from different culture can exchange their culture and there may be the feelings of social integration. Hence, we can say that there is both positive and negative impact on society due to multi culture" (Field note, May, 2011). However, the teacher did not understand the socio-emotional implications of the mother language in school. Due to the limitations in the language many children were not motivated to go to school and even if they joined a school they could not perform as well as the children from the Nepali speaking community could, which consequently forced them to leave schools (Awasthi, 2004).

Talking to the school management committee (SMC) members, including the chairperson, about the policy that is adopted by the school to address diversity. In both the research schools, SMC has given similar answers. They said that they have tried to address the need of all children but because of the lack of teachers they could not precede the teaching and learning in different languages. Though the teachers were well aware of the cultural diversity in their schools, they ignored the issue in relation to children's learning. They neither support their ethnicities nor promote discourses in their language.

Schools were not adopting the policy of use of mother language for teaching learning process in primary level in my study area. Instead, they have introduced English within the local curriculum instead of the ethnic languages; the national policy had given schools the prerogative to select either. While discussing with the teachers, they shared that they have to introduce English to keep up with the private schools where language of instruction was primarily English, even though the children are having difficulties to understand it and follow their lessons.

When asked regarding instructions in their mother tongues, teachers expressed difficulties in teaching because of their own language background. We don't have a teacher who can teach in "Tharu or Bote" said head teacher of one of the research schools. However, the head teacher said to me, "it doesn't matter to parents what the children are learning as long as they believe the children are learning something. Even if we introduce Chinese instead of English no one will come and ask us about it". This shows 
that teachers are not accommodating of the children's culture and are not incorporating the native language of the children in the learning process because of the parents' ignorance. This further leads to a lack of accountability in the teachers' regarding their disregard of the children's cultural background within the classroom environment. The discussions revealed that the teachers tended to be more imposing and underestimated the parents' knowledge. However, mother tongue based multi lingual teaching not only develop a strong educational foundation but also to it strengthen the cognitive development by providing a smooth transition from the first language to the second and the third language (Kandel, 2010).

\section{Teachers: Facilitating the Learning and Development}

Learning is an active process and is "changing the locus of control over learning from the teacher to the students" (Merriam, 1998). Learning becomes more effective if the students are presented new information with concrete examples. This can be done by the teachers. The teaching and learning process begins with the interaction between teachers and children. Without proper interaction the process becomes incomplete. I conducted observations to understand the interactions between children and the teachers, and the parents. I observed how the teachers address different children, and whether there is any difference according to the background of the children. I have found that almost all teachers want their class silent not letting children to interact among them. They have expressed that they do not like when the children made noise. So to maintain class discipline teachers become strict towards children. I observed the same situation where the students were silent and teachers were more dominating in the class.

Talking about the policies stopping physical punishment of children, "teachers do take stick with them to class room but that does not necessarily mean they use it to give punishment" one of the SMC chairpersons told me. He didn't seem inclined to disclose the nature of teachers' involvement in punishment. "There are some very strict teachers, (especially male). They hit us and sometimes punch us. They even tear our papers if they don't like our work". Asmita Bote, one of the students of Grade 4 (11 years old), shared her fear of teachers with me, "we cannot talk freely to the teachers and hesitate to go to them with our problems".

This creates a gap between teachers and students. Still, questions of why the teachers punish students and whether it is necessary is unanswered. The SMC chairpersons also think that it is the weakness of the teachers that they do not have skills required to create a proper teaching-learning environment and resort to punishment. Some of the members said that "punishment is necessary. It is because the children do not listen to the teachers. Managing a multicultural class room is quite a big feat. Mostly the children from poor families' get punishments because they are prone to misbehavior and used to it". He also added that, "teachers should know the different techniques to manage class and attract children towards the teaching and learning process. They should understand child psychology and teach effectively but they are failing to do so". The SMC chairperson also blamed the teachers for not taking good care of children. He said that neither do they teach properly nor do they understand the children's interests according to the cultural background they come from.

When I asked the teachers the same question, a teacher from one of the research schools shared that it is very difficult to teach in a multicultural classroom. The learning activities are influenced by the family background of the children. He further added," we are not scolding, but trying to say the weak points of the students. They only expect appreciations and that is not possible all the time". Bifa, a Grade 5 student from one of the schools shared, "teachers favor the more intelligent students in our class, and they don't help the less intelligent ones like us." Kanun Bote, another student also agreed to this point. He complained that teachers do not help the weak students, "They only expect excellence. We have no one to help at home. They, instead of supporting, scold us" Kamal Kumal, a student also added his remarks "I always get poor marks in exam, though; I am trying hard to get good marks and responses. Teachers are harsh to me because of this."

Schools play secondary role to families in socializing children (Brint, 1998, p. 136). The powerful mix of emotional intimacy and consistent attentiveness typical of family life cannot be duplicated by the more impersonal institutions of society (Brint, 1998). "...Teacher is 'an' authority in matters relating to the school curriculum- both subject matter and pedagogy" (Sarangapani, 2003, p. 109). Following my observation and interviews, in my research area, I found that the teachers were taking multiple roles and responsibilities. They were preparing children for an adult world (what adults expected and envisioned). They also were teaching children to use the formal language, as in the school culture.

\section{Language of Instruction}

The language of instruction is Nepali in my research area. The teachers are also giving priority to Nepali as an instructional language. While talking about the language of instruction in school, Anju, a teacher shared it is good to teach in Nepali than other languages. She further explained that, "Nepali respects everyone's languages and tries to integrate everyone by using Nepali language as a common language to speak. School is playing a role to bridge the gap in between different students from different communities by integrating them by the means of a common language."

The teacher's authority here did not support all students' language needs though there are multilingual and multicultural children in class. Another teacher shared, "As there are different students from different cultural background their languages are also different and it's difficult to communicate and make them all understand. There are some Tharu students in my class, sometime I used to speak in Tharu language to make them understand 
but again other students will be deprived." He thinks that providing an opportunity to learn in their own language is good, but the teacher cannot use many languages at limited time and using one language may deprive the learning opportunity of the students from other language backgrounds. And there were no teachers who knew multiple languages in the school.

Mr. Gopal a teacher also shared, "yes, that's why it's quite tough to treat them equally during teaching-learning process. It's difficult to manage the ratio of students from different family backgrounds". The head teacher shared they are facing language problem as they have few Magar students who do not understand and speak Nepali. This statement is further supported by Mr. Hari a teacher from one of the research schools, "Except the linguistic problem, there are social and cultural problems too. Tharu are speaking their own language at home but when they come to school they have to learn Nepali language first to be adjusted in the school. Teachers use Nepali language to communicate with other students and deliver their lessons and not the students' native language. So, due to sociocultural aspect both students and teachers feel problems in teaching-learning activities".

I noticed from my observations, children from different language background were passive in the classroom when taught the subjects like Nepali, English and Social studies. Teachers also feel the current language of instruction is difficult to follow for those children who are from different language backgrounds. They also emphasized that the teachers must know multiple languages. Teachers from both schools shared that language is one of the barriers of learning for the students. Hari a teacher shared his understanding, "I've noticed that those students who are good in linguistic subject i.e. like Nepali, they are good in other subjects too. But those who aren't good in Nepali are facing problems in the learning process in other subjects. Those who understand Nepali as second language really face lots of problem in learning. It shows that language plays an important role in education".

Rajesh a teacher shared quite different views from other teachers. He shared,"language act as a barrier only in theoretical level i.e. in a linguistic subjects (Nepali, English) but in non-theoretical subjects like Mathematics and Science it doesn't matter much". How the language matters and who is responsible in the learning process is still unanswered. However, the relation of family background is equally important in the language issue and directly affects the learning process.

A teacher from one of the research schools said, "Family background also is a crucial factor in understanding the common language, which is Nepali. For e.g. I've observed that even among the Tharus, those who are educated and professionals can easily communicate in Nepali language. Children of such background are not facing the linguistic problem as they are well versed in the language". He emphasized that the language used in home determines the proficiency in languages. My field journal also showed that the children not well versed in Nepali language were passive during English and Nepali classes. Those children, whose parents only speak Tharu or other language other than Nepali, are facing difficulties to follow the instructions at school. It is also reflected in their annual school achievements (result).

Despite the national education policy of teaching in mother language, I have found the medium of instruction is other than the mother language in my both research schools. The teachers agreed on the policy but are not taking any initiation to teach in the children's mother language. Teachers from both research schools shared, "Encouragement of mother language is good but inclusion of different languages in education is not so practical and easy in the school because it creates much problem. It will create social conflict and it is not fruitful to the society".

Are the teachers discouraging multilingual policy? Are they not supportive of the children of other ethnic and cultural backgrounds? Why do teachers only talk about Nepali language? Why are they not promoting and supporting the languages other than Nepali? I have discussed these matters with the teachers. A teacher from one of the schools further added that, "No, we totally disagree in the discouragement of culture of each individual. We really respect all cultures but in education, language inclusion is not practical. Nepali language is the national language which is spoken and understood by most of the Nepalese so this language (Nepali) is appropriate for our education system. Voice raised for the inclusion of languages in education is only due to identity crisis in the society". I have found that many teachers in both schools do not know languages other than Nepali language. This is why they are not using the children's mother tongue as the language of instruction. Gopal, a teacher realized the difficulties he faced in teaching due to not being fluent in different languages. He further added, "Backgrounds of family really affect the children in education in many ways like language, get-up, intellectual capacity, inclusion or social adjustment etc". He shared that those children who speak Nepali at home have no problem when the teachers teach in Nepali and if their Nepali is weak then their level of understanding is also poor.

\section{Children: Preparing for Learning and Development}

The reading, writing and mathematical activities of children who attend school from literate societies generate cognitive capacities different from those of tribal and village cultures where children receive little formal schooling (Berk, 2009). I found each child to be involved in a unique form of symbolic thinking developed through the activities that make culture a way of life. I have also found the same in my study area. As teachers expressed their views, "children from Nepali language background are more competent in learning activities than the children from other linguistic background". I saw that engaging children in daily household activities also supports them with the co-construction of knowledge. If these activities are linked to the information they get through the school; it would be helpful for learning and development of the children. Vygotsky's theory also supports that the cultural 
contexts play a key role in the teaching-learning and cognitive development. According to Vygotsky, (1986) through communication with more expert partners, children engage in "verbalized self-observation" reflecting on revising and controlling their own thought process (Sulivan, 2005). In this way, the engagement of parents and teachers with children prompts profound advances in the complexity of children's thinking.

Families depend on the school with expectations for developing personalities and enhancing knowledge and skills of the children. In my study area, people are dependent on the schools, and they respect it. Therefore, schools are organized and perform in ways that focus on developing personality; however, development of intimacy, emotional relation, and attentiveness are not always a priority. Children were also participating in day to day learning and development process, and were engaged in both the household works and school; it enabled them to have independent personalities. While playing with friends or engaging in household chores they can relate their school knowledge and it can be supportive for their further study.

\section{Discussion}

School, with its own set of beliefs and expected behavior from children, has been creating confusion among them regarding their "cultural capital" (Bourdieu \& Passeron, 1990). The teachers are not able to understand the knowledge and skills possessed by the parents/ community people. Had they done that, they could have been supportive for the children from multicultural backgrounds but as discussed earlier, this has created a gap in understanding between the teachers and the parents instead. Parents also think of themselves as ignorant and illiterate, further fueling the gap.

The teachers are aware of the issues of multicultural classrooms. They expressed both advantages and disadvantages to the children and to the community. There are learning opportunities as Derry (1999) said, the construction of knowledge is based on society, but because of the domination of the so-called high-class teachers, the school is creating a gap between educated and the uneducated people (as cited in Nelson 1998).

The teaching-learning process is related to the understanding of the people (Berk, 2009). I have found language to be the key tool for learning and development. If language of instruction is in a language other than the indigenous children understand, they sit in the classroom without understanding much of the teaching (UNESCO, 2011). Thus, non-Nepali speaking children have been found to be disadvantaged group in the Nepalese school system, where the medium of instruction is Nepali. As a result, their achievement at school is lower than that of Nepali speaking students (Awasthi, 2004). As per the data, the language of instruction did not address all the children because of their diversity. If a common ground for understanding is maintained, interaction between teachers and the children can become a source of learning. The interaction is currently followed as per the cultural background of the teachers. This, though helps the knowledge building, also transforms the culture and beliefs of the children.

It is found that the teachers are having trouble addressing the language and cultural differences between the children. In such situations, many children are facing challenges in the school. There is relation of home and school environment in the context of the children's learning and development. Fixed curriculum, hidden rules and preoccupied mindsets are embedded within the school environment; their own cultures, illiteracy, poverty and limited time for the children were found at the home and neighborhood environment. Though the children have their own peer group, they manage to play and use freedom; they are feeling some cultural difference between their home context and the school environment. This difference leads them to follow some adaptive strategy within the school premises. Therefore, the socio-cultural (home, neighborhood and school) environment is directly related to children' learning and development. And for this, children have to develop coping and adaptive strategy.

Children's cultural and linguistic experience at home is the foundation of their future learning, and we must build upon that foundation rather than undermine it. A child's culture determines what knowledge and skills are needed, and the culture of the people provides the tools to obtain this knowledge. The tools are the language, family background and the environment where the children grow up. To promote cultural, linguistic and intellectual capital for the society, there must be acceptance of culturally and linguistically diverse children. The respect of the linguistic, cultural, and intellectual resources that children bring from their homes to the schools and societies should also be respected. Children grow, develop and are able to learn within their environment: school, family and the community. They learn with the support of social and cultural practices, both within the family and in the community.

School is the institutional legitimized body for supporting children for their learning and development. However, there are differences in understanding and thus teachers have a low level of motivation for teaching and learning activities. In addition, when parents are convinced and ensured on the best practices and achievements, they develop learning opportunities even for the children who are in the lower strata. However, there are some barriers for the low-status groups. Teachers expressed difficulties to teach in multicultural groups of children. They are pre oriented and determined to the background of the children that influence the teaching and learning activities.

Children face the dilemma and adjustment problems in such situations resulting in confusion whether to continue or quit school. It is because of the cultural domination and the status quo of the teachers. The children from diverse cultural groups face difficulties in language, socio cultural differences and different attitudes and behaviors of the teachers. A favorable environment is necessary for the children to learn. There is need of a supportive environment for the children's learning and development. 
School management committee, teachers and parents have to work together for making child- friendly learning environment at school. However, the relationships among school and parents require to be redefined.

Schools have been contributing to the reproduction of social differentiations. It is supporting the culturally privileged students in the learning process and learning environment. Because of the preset rules, regulations and language of instruction adopted for the school, the teachinglearning processes are determined by the teachers' cultural background. Therefore, the teaching- learning process encourages the hidden rules constructed through cultural norms and power relationships.

There is a conflict between the culture of the teachers and that of the students. Both teachers and students feel difficulties in a multicultural classroom (heterogeneous group of children) because of the language and sociocultural differences. It is found that the teacher and the children are in conflict during the discourse of learning and development because of that cultural gap.

\section{Conclusion}

In conclusion, the role of school is important for facilitating learning environment for the children. It is found that the teachers' cultural understandings and the children's cultural background is not adequately addressed in the teaching-learning process. Teachers' perceptions towards learning and development and parents' role to provide for the better learning environment is situational. By exploring the roles played by teachers for promoting and providing appropriate learning opportunities, it is found related with their cultural background. Language of instruction is the language of majority of the teachers and limited teachers know how to use the children's mother language in the teaching-learning process. This has created a problem for students to be active in the teaching-learning process as they have difficulties in understanding the language needed in class. Efforts should be made and further study should be done so that the cultural differences in a multicultural class room can be adequately addressed.

\section{References}

Awasthi, L. D. (2004). Exploring monolingual school practices in multilingual Nepal. Ph. D. thesis. Copenhagen: Danish University of Education.

Ballntine, A. H. \& Spade J. Z. (2004). Schools and society: A sociological approach to education. Australia: Wordsworth.

Berk, L. E. (2009). Child development. New Delhi. PHI: Learning Private Limited.

Bourdieu, P. \& Passeron, J. (1990). Reporduction in education, society and culture. New Delhi.

Brint, S. (1998). Schools and society. New Delhi: Sage.

Burke, B. (1999/2005). Antonio Gramsci, schooling and education: The encyclopedia of informal education. Retrieved from: http://www.infed.org/thinkers/etgram. htm
CBS (2012). Population census 2011: National report. Kathmandu: Central Bureau of Statistics.

Chapman, R. S. (2010). Children's language learning; an interactionist perspective. Journal of Child Psychology, 41, 33-54

Covaleskie J. F. (1993). Power goes to school: Teachers, students, and discipline. Philosophy of Education. Retrieved from: http://www.ed.uiuc. edu/eps/PES-Yearbook/93_docs/COVALESK. HTM

Creswell, J. W. (2009). Research design qualitative, quantitative, and mixed methods approaches. New Delhi: Sage.

Denzin, N. K. \& Lincoln Y. S. (Eds.). (2005). Handbook of qualitative research. New Delhi: Sage.

Dey, I. (2003). Qualitative data analysis. A user friendly guide for social scientists. London: Routledge.

Edles, L. D. (2001). Cultural sociology in practice. USA: Blackwell Publishers.

Evans, J. L., Mayers, R. G. \& Ilfeld, E. M. (2000). Early Childhood counts: A programming guide on early childhood care for development. Washington D. C.: The World Bank.Sage.

Hammersley, M. and Atkinson, P. (1995), Ethnography, principles in practice. London:Routledge.

Huberman, A. M., \& Miles, M. B. (1983). Drawing valid meaning from qualitative data: Some techniques of data reduction and display. Quality and Quantity,17 (17), 281-339.

Kandel, P. (2010). Mother tongue based multilingual education. Nepal: Language Development Center

Madden, R. (2010). Being ethnographic: A guide to the theory and practice of ethnography. New Delhi: Sage.

Merriam, S. B. (1998). Qualitative research and case study applications in education.San Francisco: Jossey-Bass.

Munger, R. L. (2007). Children's environment and their pathways. Changing children's behavior by changing the people, place and activities in their lives. New Delhi: Prentice Hall of India private Limited.

Nelson, L. D. (1998). Herbert Blumer's symbolic interactionism. University of Colorado at

Boulder. Retrived from http://www.colorado.edu/ communication/meta-discourses/Papers/App Papers/ Nelson.htm

Papalia, D. E., Olds, S.W. \& Feldman, R. D. (2005). Human development. New Delhi: McGraw Hill.

Powell, K. C., \& Kalina, C. J. (2009). Cognitive and social constructivism: Developing tools for an effective classroom. Education, 130(2), 241.

Sarangapani, P. M. (2003). Constructing school knowledge: An ethnography of learning in an Indian village. New Delhi: Sage.

Stake, R. E. (1995). The art of case study. California: Sage.

Sulivan, C. C. (2005). Engaging with socio-constructivism: Social studies pre-service teachers learning and using historical thinking in contemporary classrooms. Austin: The University of Texas.

Vygotsky, L. (1978). Mind in society. Cambridge: Harvard University Press. 
UNESCO. (2011). Enhancing learning of children from diverse language backgrounds: Mother tongue-based bilingual or multilingual education in early childhood and early primary school years. Paris, France: Author.

Dahal, Meenakshi $\mathrm{PhD}$, has worked as an early child development expert and child rights advocates for the past eighteen years. Her research interests focus on early reading, child rights, child development, instructional design and quality of education. She is a trainer, a researcher, a presenter, and a teacher. She has involved in designing policies, strategies, guidelines, programs, training packages and resource books / materials on ECCD, child rights, basic education focusing on girls' enrollment and inclusiveness in ECED centers and schools. She has carried out a number of research projects and presented about it in various national and international Seminars. She has written a book, chapters in various books and articles in national and international journals. She has received recognition as an "Emerging Leader" and also working as an Ambassador for Decade of Childhood.

Email: meenakshi@kusoed.edu.np 